\title{
Vaginal Cuff Brachytherapy in Endometrial Cancer
}

\author{
(D) Şükriye Bilge GÜRSEL \\ Department of Radiation Oncology, Ondokuz Mayıs University, Faculty of Medicine, Samsun-Turkey
}

\section{SUMMARY}

Endometrial cancer is the most common gynecological cancer in developed countries, and its etiopathogenesis includes obesity, metabolic syndrome and unopposed estrogen effect. Therefore, the incidence is increasing and it is estimated to double in 2030. The main treatment modality is surgery, radiotherapy has role for inoperable patients and adjuvant period. Although adjuvant radiotherapy (external and/or brachytherapy) is possible, there are different literature information about indications and methods of administration. Stage and risk factors are important criteria for adjuvant treatment decision in today's routine clinical practice, grade of tumor, myometrial invasion, lymphatic vascular invasion (LVI (+)), tumor size, lymph node status, extension of tumor to cervix or vagina, age, type of surgery, and other comorbid conditions are all factors under consideration to determine the type and decision of adjuvant therapy. It has been shown that, of molecular markers which are effective on survival, POLE mutation leads to good prognosis and L1CAM and TP53 lead to poor prognosis and increased metastasis rate, and these molecular differences can also be utilized in designing adjuvant therapy in the future. When compared to the risk groups, radiotherapy reduces the risk of recurrence in the low-risk group from $5-6 \%$ to $2 \%$ and in the moderate-risk group from $12-15 \%$ to $3-6 \%$. In the high-moderate risk group, it reduces from $18-26 \%$ to $5-6 \%$. Vaginal brachytherapy is a preferred method to prevent the recurrence of vaginal cuff with far fewer side effects than external radiotherapy. The literature review showed that there are 24 different types of single application protocol and 22 different application protocols after external radiotherapy. In the treatment of endometrium cancer, vaginal cuff radiotherapy provides excellent results in disease control with a very low side effect rate, if applied properly and for the correct indication.
\end{abstract}

Keywords: Brachytherapy; cuff; endometrium.

Copyright $\odot$ 2019, Turkish Society for Radiation Oncology

\section{Introduction}

Incidence: In developed countries, endometrial cancer is the most common gynecological cancer with an incidence of 19.1/100000 in the American continent. Its incidence is 12.9-15.6/100000 in Europe and $<5 / 100000$ in Central-South Asia and Africa.[1] In general, it accounts for $4.8 \%-6 \%$ of the cancers seen in women, while it is responsible for $1 \%$ of cancer deaths in women.[1,2] Since the etiopathogenesis includes obesity, metabolic syndrome, and unopposed estrogen effect, its incidence is rapidly increasing in developed countries, and is estimated to be $42 / 100000$ in 2030.[3]

Subgroups: Type-I is the frequently encountered form of endometrial cancer. It is low grade, endometrioid, diploid, hormone receptor-positive, and has good prognosis. Type II endometrial cancers are non-endometrioid, high grade, aneuploid, TP-53 mutated, hormone receptor negative tumors. They include serous, clear cell, and undifferentiated subgroup, and 
have poor prognosis and high metastasis rates.[4,5] Type-I endometrial cancer is associated with hyperestrogenism and endometrial hyperplasia, and it is mostly seen in the pre-perimenopausal age group, whereas type II is not associated with estrogen, but it develops in advanced age and in the presence of an atrophic endometrium. Type II constitutes $10 \%$ of cases, whereas it is estimated that it is responsible for $50 \%$ of recurrences.[6,7]

Nowadays, molecular data support that type-I carcinomas are associated with genetic alterations in PTEN, KRAS, CTNNB1, and PIK3CA and MLH1 promoter hypermethylation, whereas serous carcinomas frequently harbor TP53 mutations. $[5,8]$ While L1 adhesion protein (L1CAM) is found to be a strong predictor of distant metastasis, it has an excellent prognosis in POLE mutant endometrial cancers, which may possibly be under unnecessary adjuvant therapy. $[9,10]$

Since it is not possible to explain all the difference in prognosis with the present dualistic model, the Cancer Genomic Atlas research network has identified four molecular subtypes.[10]

1. (POLE) ultra-mutated tumors

2. Microsatellite unstable tumors

3. Tumors with high number of copy with TP53 mutation

4. The remaining tumors without these alterations

\section{Treatment of Endometrial Cancer}

Surgery: Nowadays, surgery is the primary treatment modality in endometrial cancer.[4] A total hysterectomy including both tubes and ovaries is the gold standard for the treatment of stage I endometrial cancer, and this treatment is valid for most cases. This can be done by minimally invasive (laparoscopy or robot-assisted surgery) transvaginal or laparotomic methods. The surgical approach in lymph nodes for surgical staging is one of the most variable subjects around the world. From not doing a nodal evaluation, sentinel nod mapping to complex pelvic \pm paraaortic lymph node dissection, there is a wide range of approaches. The guiding factors are histological type, preoperative staging, grade, MRI findings, and intraoperative histological findings. To determine myometrial thickness for the decision of lymph node dissection before the operation in patients with stage I, grade 1 , and 2 endometrial cancer, it is recommended to perform at least one of the ultrasonographic examination and/or MRI and/ or intraoperative pathologic myometrial thickness determination by a specialist.[4] Paraaortic nodal evaluation is recommended, especially for deeply invasive, high grade, and type II disease.[11] The extent of lym- phadenectomy varies according to clinical disciplines and surgeons, but it has not yet been demonstrated by a prospective randomized study that a surgical staging by lymphadenectomy provides a survival advantage.

Lymphadenectomy was investigated in two large prospective studies. The MRC ASTEC study has two arms: 704 patients underwent standard surgical treatment [(total abdominal hysterectomy - bilateral salpingo-oophorectomy (TAH+BSO), peritoneal washings and palpation of paraaortic lymph nodes], and 704 patients underwent lymphadenectomy in addition to standard surgery. The five-year overall survival was similar among these arms (81\% in standard surgery, $80 \%$ in lymphadenectomy, $\mathrm{p}=0.31$ ). Furthermore, fiveyear relapse-free survival was better in the standard surgery arm $(79 \%$ vs. $73 \%, \mathrm{p}=0.017)$. However, the limitation of this study is that the lymphadenectomy protocol does not include the entire pelvic paraaortic nodal region.[12]

In another Italian prospective study, patients diagnosed with early-stage endometrial cancer were randomized into groups with systemic pelvic lymphadenectomy (264 patients) and without lymphadenectomy (250 patients). While the rate of the diagnosis of nodal involvement was higher in the lymphadenectomy arm $(13.3 \%$ vs. $3.2 \%, \mathrm{p}<0.001)$, this result did not affect progression-free survival rate $(81.7 \%$ vs. $81.7 \%, \mathrm{p}=0.68)$ and did not change overall survival rate $(85.9 \%$ vs. $90 \%, p=0.50)$. In addition, the rate of complications was lower in women without lymphadenectomy ( 34 patients vs. 81 patients, $\mathrm{p}=0.001$ ). [13] Although there is no clear survival advantage proved by prospective randomized trials, older retrospective series had showed survival advantage for survival by lymphadenectomy.[14,15] SEPAL, a Japanese study that evaluated paraaortic lymphadenectomy retrospectively in patients with endometrial cancer, included 671 patients with moderate to high relapse risk treated between 1986 and 2004. In this study, 325 patients underwent standard surgery+pelvic lymphadenectomy and 346 patients underwent pelvic+paraaortic lymphadenectomy. The overall survival rate was significantly higher in the pelvic paraaortic lymphadenectomy group $(\mathrm{p}=0.0005)$. [14]

Standardization of the definition of appropriate lymphadenectomy is still ongoing. The number of lymph nodes removed in most solid tumors is considered to be a marker for the adequacy of lymphadenectomy. In two retrospective reviews, it has been concluded that removal of at least 10 and 12 lymph nodes in the endometrium increases survival.[16,17] Therefore, it is often recommended to remove at least 10 lymph nodes.[16-18] Lymph node sampling has low 
sensitivity.[19] The Mayo clinic reported that the rate of isolated paraaortic lymphadenopathy without pelvic lymph nodes is up to $16 \%$ in high-risk patients.[11] Surveillance, Epidemiology and End Results (SEER) analyses reported that $\geq 10-11$ lymph node removal provided a limited survival advantage in the low-risk group in 16,995 patients with endometrial cancer, and provided a good survival advantage in the moderate- and high-risk group.[20] However, limb edema was reported as $8 \%-50 \%$ in cases with lymphadenectomy.[21]

Consequently, the European Society for Radiotherapy and Oncology (ESTRO) consensus recognizes that lymphadenectomy is particularly useful in shaping the adjuvant treatment approach.[4] In most national and international guidelines, lymphadenectomy has been excluded from routine practice for patients with low and moderate-risk because of the lack of studies with high levels of randomized evidence on survival advantage and related morbidity rates. However, it remains the focus of interest in high-risk patients.

Radiotherapy: Although radiotherapy has become a major component of treatment for inoperable or recurrent endometrial cancer, adjuvant radiotherapy frequently comes up in operated patients as external beam radiation therapy (EBRT) or vaginal brachytherapy (VBT).

\section{Indication, Risk Determination, and Patient Selec- tion}

Stage and risk factors are important criteria. To determine the type and decision of adjuvant therapy, grade of tumor, myometrial invasion, lymphatic vascular invasion (LVI (+)), tumor size, lymph node status, extension of tumor to cervix or vagina, age, type of surgery, and other comorbid conditions are the factors to be considered.

The type of surgery frequently affects the choice of adjuvant therapy. The frequency of external radiotherapy was lower in patients who underwent lymphadenectomy. The decision of external radiotherapy is particularly relevant for patients with moderate-risk for recurrence.

It is necessary to evaluate the main studies to understand the risk factors and groups.

In their study on 540 patients with stage I endometrial cancer (Norwegian study), Aalders et al. applied a low-dose rate (LDR) VBT in one group and added additional EBRT in the other group. They noted that vaginal and pelvic recurrence decreased from $6.9 \%$ to $1.9 \%$ in the second arm $(\mathrm{p}<0.01)$. In addition, it was found that metastasis rates were higher, and the addition of EBRT did not increase the five-year overall survival in the second group.
Grade 3,>1/2 myometrial thickness involvement is defined as subgroups in which external EBRT may be advantageous.[22]

Onsrud et al. reported no survival difference $(\mathrm{p}=0.186)$ in the Norwegian study after a median follow-up of 20.5 years, and, on the contrary, reported higher mortality rates in patients under 60 years of age who applied EBRT. The increase in the incidence of secondary cancer in patients undergoing radiotherapy under 60 years of age is the late result of this study with an HR of 2.02 (95\% CI 1.30-3.15).[23]

The PORTEC-1 (Postoperative radiotherapy for endometrium cancer) study was conducted between 1990 and 1997; and 19 out of 20 Dutch oncology centers participated in this study. That study aimed to evaluate the effect of adjuvant pelvic radiotherapy on local recurrence and overall survival in stage I endometrial cancer, and 714 patients were randomized in this study. This study has two arms: TAH+BSO without lymphadenectomy and 46 Gy EBRT in addition to $\mathrm{TAH}+\mathrm{BSO}$ without lymphadenectomy. The eligibility criteria were endometrial cancer diagnosis, any age, postoperative FIGO stage I and if Grad 1 than deep myometrial invasion ( $>50 \%)$, if Grad 2 than any invasion, or if Grad 3 than superficial invasion. The locoregional control rate was markedly better in the EBRT arm (4\% vs. $14 \%, \mathrm{p}<0.001)$. It was also found that $74 \%$ of the recurrences are at the top of the vagina. The five-year overall survival rates were similar in the EBRT arm and in the follow-up arm with rates of $81 \%$ and $85 \%$, respectively $(\mathrm{p}=0.31$ ). This was attributed to good salvage rates after recurrences. In patients over 60 years of age, a marked increase in locoregional recurrence rates $(\mathrm{p}=0.003)$ and cancer-related mortality $(\mathrm{p}=0.02)$ was reported. Subsequently, the 15 -year outcomes of PORTEC-1 study were published. At the end of 15 years, locoregional recurrence rate was reported as 5.8\% in EBRT arm and $15.5 \%$ in follow-up arm $(\mathrm{p}<0.001)$. At the end of 15 years, overall survival rate was $52 \%$ in EBRT arm and $60 \%$ in follow-up arm $(\mathrm{p}=0.14) .[24,25]$ In addition, the evaluation of quality of life in the PORTEC-1 study showed that the rate of side effects such as urinary symptoms (urgency, need to be close to the toilet, incontinence) and bowel symptoms (fecal urgency, leakage, diarrhea, restrictions in daily activities because of bowel irritability) increased from $4 \%$ to $26 \%$ (in fact, most were grade 1 ) with external RT (p<0.0001).[26]

MRC ASTEC and NCIC CTG EN.5 randomized trials ( $\mathrm{n}=905)$ [27] and Gynecological Oncology Group (GOG)-99 ( $\mathrm{n}=392)$ [28] also compared postsurgical follow-up and EBRT approaches. Cochrane meta-analysis of these studies showed that although 
there was a decrease in vaginal and pelvic recurrence rates with EBRT, there was no overall survival difference.[29] In the GOG-99 trial, age, depth of myometrial invasion, LVI (+), and grade were found to worsen prognosis.[28] In the light of these studies, postoperative risk groups were defined in endometrial cancer (Table 1).

Today, the ESTRO guideline and the defined risk groups in the guideline are frequently used in treatment management and risk assessment.[4]

\section{Low-Risk (IA Gr 1-2, LVI (-))}

The subgroup analyses in the low-risk group included in the large randomized studies showed that adjuvant radiotherapy did not provide an advantage in this group.[4,24,25,27,28] In another randomized study, 645 patients with low-risk endometrial cancer were randomized to post-surgical VBT and follow-up arms. The recurrence rate in the follow-up arm was found to be $5 \%$, indicating that VBT does not provide any benefit.[30] In randomized studies, recurrence rate in lowrisk patients is around $4 \%$, indicating that there is no benefit from adjuvant radiotherapy.

\section{Moderate-Risk, High-Moderate-Risk}

The GOG-99, PORTEC-1, MRC ASTEC, NCIC CTG EN.5 trials, and Cochrane meta-analysis showed that EBRT reduced pelvic recurrence to one-third, but it did not provide a survival advantage, resulting in increased cost and high toxicity, especially in the gastrointestinal

Table 1 Risk groups in endometrial cancer by study and groups

\section{Study, Group}

\begin{tabular}{lcc} 
& Low & Moderate \\
\hline Study Group & Risk group & \\
& Low & Moderate \\
PORTEC-1 & Gr $1-2, \mathrm{Ml}<50 \%, \mathrm{EC}$ & Stage I, GI EC \\
& & and $\mathrm{Ml} \geq 50 \%$ \\
& & $\mathrm{Gr} 2$ \\
& & Gr 3 and $\mathrm{Ml}<50 \%$
\end{tabular}

PORTEC-2

$\begin{array}{lcc}\text { GOG-99 } & \text { Stage IA, Gr } 1-2, & \leq 50 \text { years and } \leq 2 \text { PRF } \\ \text { (PRFs) } & \text { endometrioid } & 50-69 \text { years } \leq 1 \text { PRF } \\ \text { Gr } 2-3 & & \geq 70 \text { years without PRF }\end{array}$

$\mathrm{Ml}>2 / 3$

ESTRO 2016

Stage I endometrioid
\[ \begin{array}{c}\text { Gr } 1-2 \\ \text { MI } \geq 50 \% \\ \text { LVI (-) }\end{array} \]

Stage IA-IB Gr 3, endometrioid Stage IC-IIA, Gr 1-2

\section{Risk group}

High-moderate

High

High-moderate
EC and two of the three factors
$>60$ years old
Gr 3
MI $\geq 50 \%$
$>60$ years old
Stage IC, Gr $1-2$
Stage IB, Gr 3
Stage IIA (excluding those
with MI $>50 \%$ and Gr3)
Any age and 3 PRF
$50-69$ years $\geq 2$ PRF
$\geq 70$ years and $\geq 1$ PRF

Stage I endometrioid
Gr 3
MI $<50 \%$
Any LVI or
Gr $1-2$
LVI (+)
Any MI

High

Stage III-IV

Uterine serous or clear cell carcinoma with any stage

Stage III-IV, any histology and grade Uterine serous and clear cells, Stage IB, $\mathrm{Gr}$ 3, endometrioid Stage I endometrioid Gr 3

$\mathrm{Ml} \geq 50 \%$

Any LVI Stage II

Stage III endometrioid without residues Non-endometrioid 
tract.[24,25,27-29] In the ASTEC study, VBT was applied to $50 \%$ of the follow-up arm, although VBT was released in both arms. Vaginal recurrence rates were similar $(4 \%$ vs. $7 \%)$ in patients who underwent and did not undergo EBRT. Kong's Cochrane meta-analysis shows that EBRT provides a $6 \%$ reduction in absolute risk, suggesting that each 16.7 treatment rescues one patient from locoregional recurrence.[29]

Then, the PORTEC-2 study, which included only high-moderate-risk patients, investigated 427 patients on whether VBT could replace EBRT with acceptable toxicity and quality of life, and this study confirmed the non-inferiority hypothesis.[31] Similar results were reported from the Swedish study, where Sorbe et al. evaluated endometrial cancer cases in the moderate-risk group (EBRT+VBT vs. VBT).[32]

The PORTEC-2 study was designed as a non-inferiority study aiming to compare two adjuvant radiotherapy schemes as a phase- 3 study. Then, 427 patients in the high-moderate-risk group of PORTEC were randomized to EBRT (46 Gy in 23 fractions) or VBT [high-dose rate (HDR) 7 Gyx 3 fractions or LDR 30 Gy, $0.5 \mathrm{~cm}$ deep] after TAH-BSO without lymph node dissection. Five-year vaginal recurrence was similar with VBT and BRT, with rates of $1.88 \%$ and $1.6 \%(\mathrm{p}=0.74)$, respectively. The pelvic recurrence rate was higher in the VBT group with a rate of $0.5 \%$ compared to $3.88 \%$ $(\mathrm{p}=0.02) \cdot[31]$

The 10-year outcomes of PORTEC-2 were published in 2018, and vaginal recurrence was still similar in the VBT and EBRT arms, with rates of $3.4 \%$ and $2.4 \%(\mathrm{p}=0.55)$, respectively. The pelvic recurrence was observed in 13 females in the VBT group, and in two females in the EBRT group (6.3\% vs. $0.9 \%, \mathrm{p}=0.004)$. The 10 -year distant metastasis rates were $10.4 \%$ and $8.9 \%$, respectively $(\mathrm{p}=0.004)$. In conclusion, isolated pelvic recurrence rates were similar between groups ( $2.5 \%$ vs. $0.5 \%$, respectively, $\mathrm{p}=0.10)$. The 10 -year overall survival rate was $69.5 \%$ vs. $67 \%(\mathrm{p}=0.72)$, and the endometrial cancer specific survival rate was $88.2 \%$ vs. $90.9 \%$ ( $\mathrm{p}=0.42$ ), respectively. According to the central pathology and the re-categorization of the risks, $82.7 \%$ of the patients were originally identified in the highmoderate-risk group. Molecular risk factors were also assessed in this evaluation.[33]

Many cohort studies have identified grade 3 and LVI $(+)$ as the greatest risk factors for recurrence. $[34,37]$ This result is also shown in the current data analysis of PORTEC-1 and 2 trials.[37] However, in the PORTEC-2 trial, most of the patients in the high-moderate-risk group consisted of those with deep myometrial invasion but grade 1-2 and LVI (-) carcinoma, which are nowadays evaluated in the moderate-risk group rather than in the high-moderate-risk group. In both groups, the five-year vaginal recurrence rate was below $2 \%$. The distant metastasis and survival rates were similar. According to the results of this non-inferiority study, VBT is a highly preferred standard treatment with less side effect profile in patients with stage I endometrial cancer, that is in the high-moderate-risk group.[31] Follow-up can be performed with a risk of recurrence up to $20 \%$, but it is reported that patients prefer radiotherapy even if it provides a $5 \%$ benefit.[38]

Although there are big randomized trials that have over 900 patients, the power of these studies is still not sufficient to determine the survival advantage. The National Cancer Database (NCDB) demonstrated the survival advantage of postoperative radiotherapy in both high-moderate-risk and high-risk patients in a study that collected data from 1500 centers in the United Nations. They reported that the mortality risk in more than 132.000 patients decreased by $22 \%$ with radiotherapy. The presence of radiotherapy has also been shown as an independent factor on overall survival in multivariate analysis. [39] The SEER database showed that EBRT or VBT without lymph node dissection provides survival advantage in both moderateand high-risk patients.[40] However, further analysis including 58,172 patients revealed that there was no decrease in cancer specific mortality rates.[41] In conclusion, it was observed that RT did not increase overall survival in moderate-risk patients. This recurrence may be explained by the high likelihood of complete survival of the disease with EBRT and VBT, and preferably RT may not be administered to this group. However, it should be kept in mind that the morbidity of rescue therapies will be higher.

In the current classification, tumors with $\geq 50 \%$ invasion, at grade $1-2$ and with LVI (+), and with $<50 \%$ invasion, at grade 3 and with or without LVI (any) are considered in the high-moderate-risk group.

\section{High-Risk Endometrial Cancer}

This group has a higher likelihood of pelvic recurrence and distant metastasis, and it includes both endometrioid and non-endometrioid group. This group included advanced-stage patients with $\geq 50 \%$ myometrial invasion, at grade 3 and more locoregional recurrence. NCDB reported that VBT increased survival rate in patients with high-risk stage IA.[39] The EBRT+RT boost regimen rather than VBT alone is recommended as a treatment 
protocol in this group, but there are publications with a low level of evidence about the type of radiotherapy. The SEER database reported that radiotherapy (independent of type) provided a survival advantage in patients included in the high-moderate-risk and high-risk groups according to the PORTEC risk grouping.[41]

In the GOG-249 study, both high-moderate-risk and high-risk patients were randomized to three cycles of carboplatin/paclitaxel arms after EBRT and VBT. It was shown that adjuvant chemotherapy did not contribute to progression-free survival. The results were then published as poster presentation.[42] In this group, the opinion that the addition of EBRT to LVI (+) patients who have not undergone surgical lymph node staging, and the use of VBT as adjuvant therapy in the remainder is dominant.

The NSGO-EC-9502/EORTC 55991 and MaNGOILIODE III randomized studies investigated the effect of chemotherapy in this group, and the analysis identified an increase in five-year disease-free survival and an increase trend in overall survival.[43]

The PORTEC-3 study, which examined 660 patients with high-risk group of endometrial cancer, randomly administered 48.6 Gy external radiotherapy in one arm and chemotherapy followed by concomi- tant cisplatin-based chemoradiotherapy in the other arm. Consequently, the addition of chemotherapy had no effect on five-year survival, with even more toxicity.[44]

When compared to the risk groups, radiotherapy reduces the risk of recurrence in the low-risk group from $5 \%-6 \%$ to $2 \%$ and in the moderate-risk group from $12 \%-15 \%$ to $3 \%-6 \%$. In the high-moderate-risk group, it reduces from $18 \%-26 \%$ to $5 \%-6 \%$. $[25,26,28]$

\section{Advanced-Stage Endometrial Cancer}

Although there were fewer studies on radiotherapy in stage III/IV patients, the SEER retrospective analysis evaluated 1577 patients, and reported a higher fiveyear overall survival in patients undergoing EBRT or EBRT+VBT.[45]

NCDB revealed that the addition of VBT to EBRT in patients with stage III endometrial cancer and cervical involvement provided a survival advantage (HR 0.86).[46]

\section{Patient Involvement in Determining the Indication} In their study on behalf of Dutch Gynecologic Oncology Group, Kunneman et al. questioned the minimally acceptable level of benefit for the VBT selection to

\section{Table 2 ESTRO Guide for Adjuvant Treatment}

\begin{tabular}{|c|c|c|}
\hline Risk Group & Definition & $\begin{array}{l}\text { Adjuvant Treatment (Evidence Level, } \\
\text { Grade of Recommendation) }\end{array}$ \\
\hline Low & $\begin{array}{l}\text { Stage I endometrioid, grade } 1-2 \text {, } \\
\text { myometrial invasion }<50 \% \text {, LVI (-) }\end{array}$ & Follow-up $(I, A)$ \\
\hline Moderate & $\begin{array}{l}\text { Stage I endometrioid, grade } 1-2 \text {, } \\
\text { myometrial invasion } \geq 50 \% \text {, LVI (-) }\end{array}$ & $\begin{array}{l}\text { a) Brachytherapy (I, B) } \\
\text { b) Follow-up (especially <60y) (II, C) }\end{array}$ \\
\hline High-moderate & $\begin{array}{l}\text { Stage I endometrioid, grade } 3, \\
\text { myometrial invasion }<50 \%, \mathrm{LVI}(-), \\
\text { or Stage I endometrioid, grade } 1-2, \\
\text { LVI (+) and any myometrial invasion }\end{array}$ & $\begin{array}{l}\text { 1. Surgical nodal staging performed, lymph node (-) } \\
\text { a) Brachytherapy (III, B) } \\
\text { b) Follow-up (III, C) } \\
\text { 2. No surgical nodal staging } \\
\text { a) External radiotherapy (especially if LVI (+) (III, B) } \\
\text { b) Brachytherapy (Grade } 3 \text { and LVSI (-)) (III, B) } \\
\text { 3. The benefit of systemic therapy is unclear (III, C) }\end{array}$ \\
\hline High & $\begin{array}{l}\text { Stage I endometrioid, grade } 3, \geq 50 \%, \text { LVI }(- \text { or }+ \text { ) } \\
\text { Stage II } \\
\text { Stage III endometrioid, no residual disease }\end{array}$ & $\begin{array}{l}\text { 1.Surgical nodal staging performed, lymph node (-) } \\
\text { a) Limited area external radiotherapy (I, B) } \\
\text { b) Brachytherapy (III, B) } \\
\text { c) There are studies about systemic treatment (II, B) } \\
\text { 2. No surgical nodal staging } \\
\text { a) External radiotherapy (III, B) } \\
\text { b) Brachytherapy as a boost (IV, C) } \\
\text { c) Sequential adjuvant chemotherapy (II, C) } \\
\text { d) Both external radiotherapy and chemotherapy (II, B) }\end{array}$ \\
\hline Advanced & $\begin{array}{l}\text { Stage III residual disease is available } \\
\text { Stage IV }\end{array}$ & \\
\hline
\end{tabular}


the patients and health workers. This rate was $0 \%$ for patients and $8 \%$ for physicians $(\mathrm{p}<0.001)$. Thus, most patients would like to receive VBT even if there is a possibility of zero benefit.[38] This corresponds to the reluctance to participate in the follow-up arm in the PORTEC-4.[47]

\section{Treatment Recommendations}

The American Society for Brachytherapy (ABS) published consensus guidelines on operated endometrium in 2000 and 2012. [48,49]

The American Society of Radiation Oncology has published evidence-based radiotherapy recommendation guidelines in 2014.[50]

In 2016, the ESTRO consensus was published, and Table 2 shows treatment recommendations according to the risk categories of this group.[4]

\section{Treatment Preparation and Applicator Selection}

Before radiotherapy, the physician should inform the patient about the risks, benefits, goals, and alternatives treatments. Prior to treatment, it is important to perform pelvic examination and to check that the vaginal apex is healed and the small intestine is not herniated from the vaginal apex. The proposed schedule is not to start before 4 weeks and not to exceed 12 weeks. It should be noted that improvement in robotic- or laparoscopic-assisted vaginal hysterectomy might take more time to heal.[49]

Prior to the placement of the applicator, a vaginal examination should be performed to assess the vaginal structure, width, size, presence and shape of healing (vaginal apex), and presence of recurrence, albeit rarely. Explaining the procedures to the patient and applying lubricant (such as xylocain gel) to the applicator will facilitate the procedure. Rarely, pain relievers, anxiolytics, or moderate sedation are required for brachial brachytherapy. Applying a clip to the apex to check the applicator's full fit and placement in the apex may be an appropriate method, but it does not always give the desired result because of the possibility of the clips falling or being displaced. In deciding the diameter of the cylinder, it is recommended that the physician first places one finger on the vagina and gently presses the perineal muscle to make the patient take deep breaths and relax. After the patient tolerates it and relaxes, the second finger is advanced and rotated to relieve the introitus. If this maneuver can be easily done, the 3.5 $\mathrm{cm}$ cylinder will be suitable. If the vagina is too relaxed because of multiparity, then a diameter of $4 \mathrm{~cm}$ will be chosen. However, if the entry of the second finger is not allowed, it would be appropriate to select the cylinder with a diameter of $2.5 \mathrm{~cm}$. For the remaining cases, $3-\mathrm{cm}$ cylinder is selected. After the fixation, check must also be done before applying the treatment. The planning tomography (CT) will show the compliance of the vagina and applicator. ABS suggests the largest applicator that can be placed.[49]

Humphrey et al. studied the CT image of 103 patients, and detected 67 air gaps in 38 patients. They reported that this ratio was lowered to 11 patients by placing larger cylinders in spaces larger than $2 \mathrm{~mm}$ and required repositioning, and that there is a significant air gap exceeding $2 \mathrm{~mm}$ in only $7 \%$ of patients.[51] In two other studies, air gaps exceeding $2 \mathrm{~mm}$ were reported with a rate of $32 \%$ and $72 \%$.[52,53] However, most of them have little clinical significance, and were reported to include only $0.86 \%$ of the vaginal surface.

The structure as well as the diameter of the applicator is also important for the implementation of the optimal VBT. In the literature, single-channel cylinders (83.2\%) are used for most of the patients.[54] However, a single simple applicator cannot treat all vaginal types and postoperative anatomical variants. In most patients, the vagina is cylindrical in the postoperative period, and it is possible to treat it with a vaginal cylinder of the appropriate size. A vaginal cylinder of a very small diameter than the vaginal size may lead to the formation of air gaps or tissue folds, resulting in dose drops in these regions. It should be kept in mind that multi-catheter cylinders may reduce the rectum and bladder dose, but may cause a dose increase in the vaginal mucosa.[55]

In some cases, the vaginal apex can be seen as a "dog ear" shaped pocket because of the vaginal fornix remnants. These conditions can be best treated with vaginal molds, multichannel applicators, or ovoid applicators.[56,57] (Fig. 1)

\section{Dose Rate}

In the past decades, $69 \%$ of the patients were treated with HDR, but this rate has reached $96 \%$. Fayed et al. compared the results of HDR and LDR, and revealed that there was no difference between two modality for local control and total survival rates.[58]

\section{Dose Fractionation Schemes}

There is a large difference in the fractionation and dose scheme in the literature, and 24 protocols for VBT alone and 22 protocols for boost therapy were recorded. The EQD2 dose is between 36 and $48 \mathrm{~Gy}$ for VBT alone and between 57 and 69 Gy in combination with EBRT.[29,54] 


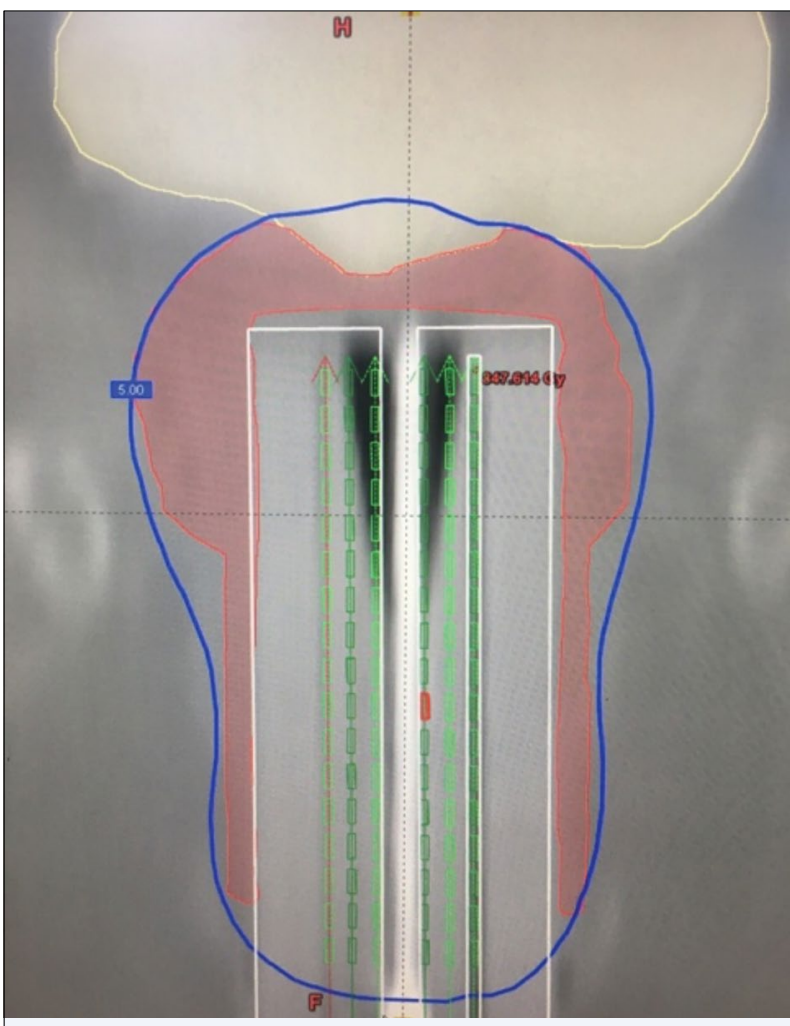

Fig. 1. Better coverage of the lateral regions of apex with the multichannel applicator.

VBT alone: The dose can be varied according to the length and width of the vagina to be irradiated. The recommendation is that the dosing point, line, and volume should be clearly indicated. The doses of $7 \mathrm{~Gy}$ in three fractions at $0.5 \mathrm{~cm}$ are the frequently preferred scheme in the PORTEC-2 study. MD Anderson Cancer Center prefers 6 Gyx 5 fraction scheme, whereas DanaFarber Cancer Institute 4 Gyx 6 fraction scheme on the vaginal surface. $[25,54]$ There is no literature comparing the fractionation schemes or showing the superiority of these schemes against each other.

POTREC-4 is a study designed to determine the optimal dose in VBT alone. The patients with high-moderate-risk endometrial cancer in the postoperative period were randomized to follow-up and VBT arms; and in the VBT arm, a second randomization was performed into $7 \mathrm{~Gy}$ and $5 \mathrm{~Gy}$ in three fractions at a depth of $0.5 \mathrm{~cm}$. However, because of the bad choice of follow-up arm for high-moderate-risk endometrial cancer, the study has to be closed early. The study is planned to continue in the other two arms.[47] For an optimal schema, there is need for more phase three studies.

VBT after EBRT: Commonly used schemas include 6 Gyx3 (RTOG 0921) regimen after 45 Gy EBRT on the vaginal surface and 6 Gyx2 (RTOG 0418) regimen after 50.4 Gy EBRT on the vaginal surface. If there is a positive margin or disease recurrence, the dose should be increased. It is often useful to reduce the size of the fraction if the diameter of the fitable cylinder diameter is low.

\section{Target and Dose Identification}

Length: There are several studies on the size of the treatment area, which often ranges from 1 to $10 \mathrm{~cm}$.[59,60] However, most commonly used protocols were applied to the proximal $3-5 \mathrm{~cm}$ of the vagina or proximal $1 / 3-1 / 2$ of the vagina, while no consensus could be determined. The recommendation of ABS is $3-5 \mathrm{~cm}$ proximal to the vagina.[49] The approach to treating the entire vagina is in the process of being discontinued because of the very low rate of distal vaginal recurrences and the increased incidence of side effects.[54] Since the risk of distal vaginal recurrence increases in the presence of papillary serous and clear cell histology and in grad 3 disease or in the presence of extensive lymphovascular invasion, treatment of the entire vagina can be preferred. In their study in which proximal vagina, vaginal apex, proximal half of vagina and whole vagina were treated, Kloetzer et al. reported no difference in survival and vaginal recurrence rates.[61]

Depth: It is known that $50 \%$ of the lymphatic channels are located $1 \mathrm{~mm}$ below the mucosa, and that $95 \%$ of the total is located at a distance of $3 \mathrm{~mm}$ below the surface. $[62,63]$ This finding supports the idea that the target is properly covered with the dose defined at the depth of $0.5 \mathrm{~cm}$. When the dose is defined on the surface, the surface dose is more homogenous, whereas the surface dose is more heterogeneous when the dose is defined at depth $(81 \%-172 \%)$.

The ABS recommends reporting of both the surface dose and the dose at a depth of $0.5 \mathrm{~cm}$, regardless of where the dose is defined. Furthermore, wherever the dose is defined, it is recommended that the optimization point be placed on both the top and lateral sides in treatment planning.[49]

In the 2014 report of ABS, it was stated that the most preferred VBT alone regimen is three fractions with $7 \mathrm{~Gy}$ fraction size at a depth of $0.5 \mathrm{~cm}$, while the most preferred post-EBRT regimen is three fractions with $5 \mathrm{~Gy}$ fraction size at a depth of $0.5 \mathrm{~cm}$. [54]

Percentage depth dose has more variability when using $2-\mathrm{cm}$ cylinders. To convert a dose at $0.5 \mathrm{~cm}$ depth into a surface dose, a formula as follows can be used.[64]

$\mathrm{M}$ (magnification factor) $=1.00+0.64 /$ treatment length $+1.23 /$ cylinder diameter). 

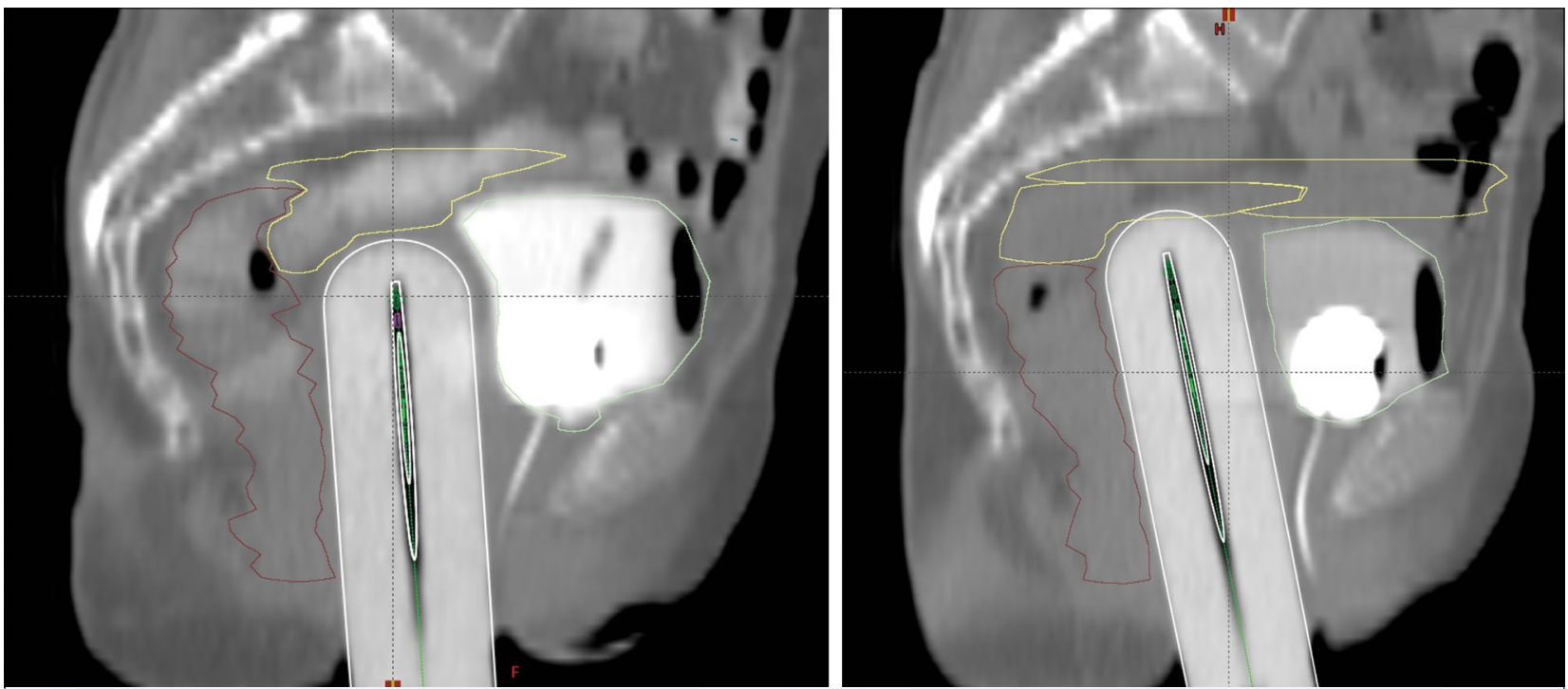

Fig. 2. Sagittal tomography images of the applicator in neutral position and horizontal position in the same patient. In addition, the intestines have been tried to be kept away, increasing the bladder fullness.

\section{Doses of Organ at Risk}

A study that analyzed the patient position revealed that treatment of the patient in neutral position lowered the doses of rectum D1cc and 2cc compared to the gynecological position. (4.69 vs. 5.66 Gy and 4.24 vs. 5.14 Gy, respectively).[65]

The placement of the applicator in the horizontal plane is advantageous in terms of both patient comfort and not increasing the dose of rectum or bladder. There are studies reporting the effect of the placement angle of the cylinder on the dose of rectum. In these studies, it has been reported that the positioning of the top of the cylinder toward the rectum increases the dose, but the parallel position of the cylinder to the horizontal axis further decreases the dose of the rectum.[66,67] (Fig. 2)

Although bowel fullness has been reported to increase bowel dose, there was no significant difference in dose parameters in the protocols containing an enema treatment one evening before and one in the morning of treatment. $[68,69]$

The comparison of the full bladder $(180 \mathrm{cc})$ and empty bladder revealed that the fullness of the bladder reduces D50\% values of the bladder and reduces the dose of the small intestine from $36.7 \%$ to $21.4 \%$.[70] In another study comparing the full and empty bladder plans in 15 patients, bladder filling was reported to increase the distance between the cylinder and the small intestine from 1.2 to $1.68 \mathrm{~cm}(\mathrm{p}=0.006)$, but it was observed that this maneuver increased the bladder D2cc by $18.7 \%$.[71] Stewart et al. demonstrated that treatment of a full bladder reduced the maximum dose of the bladder and reduced the volume of bladder that received $70 \%$ of the defined dose. In addition, a full bladder allows the adjacent small bowel to move away from the vaginal cylinder.[72] (Fig. 2)

\section{Number of Planning}

Today, approximately $80 \%$ of the plans are designed as three-dimensional (3D), while up to $75 \%$ are carried out only through the plan in the first application. [54] The ABS guide does not recommend planning with every fraction because we have quite a fixed geometry. Creating a plan in each application increases the cost by $35 \%$ and does not provide a dosimetric advantage. [73] Studies comparing planning in each fraction versus the first fraction showed that the dose was not reduced in organ at risk, but the cost was increased.[73,74]

Chapman et al. compared magnetic resonance (MRI) and CT images of the patients, and they found that with MRI, a volume of $1 \mathrm{~cm} 3$ and more received less than $75 \%$ of the defined dose at least in $69 \%$ of patients.[75] Low-dose areas often located on the top of the vagina, where the cylinder could not be located exactly because of suture materials.

In a study comparing two-dimensional (2D) and 3D treatment planning, the target dose was the same, while the critical organ doses were reported to be lower with 3D planning.[76]

$\mathrm{ABS}$ recommends that there is a clear and written directive, which is dated and signed and has information about treatment area, source, dose defined per 
fraction, total dose, and fractionation scheme. The location of the absorbed dose must be clearly specified. The type of applicator, the shape of the optimization, the dwell position number and position, dwell weights, and isodose distribution should also be documented. The doses of the adjacent organ at risk, especially the bladder and rectum, should also be documented.[49]

\section{Conclusion}

In the treatment of endometrium cancer, vaginal cuff radiotherapy provides excellent results in disease control with a very low side effect rate, if applied properly and for the correct indication.

Peer-review: Externally peer-reviewed.

Conflict of Interest: There is no conflict of interest.

Financial Support: This study hasn't got any financial support.

\section{References}

1. WHO. GLOBOCAN 2012: Estimated cancer incidence, mortality and prevalence worldwide in 2012. Avilable at: http://globocan.iarc.fr/Pages/fact_sheets_ population.aspx. Accessed 3 Apr 3, 2015.

2. Jemal A, Siegel R, Xu J, Ward E. Cancer statistics, 2010. CA Cancer J Clin 2010;60(5):277-300.

3. Sheikh MA, Althouse AD, Freese KE, Soisson S, Edwards RP, Welburn S, et al. USA endometrial cancer projections to 2030: should we be concerned? Future Oncol 2014;10(16):2561-8.

4. Colombo N, Creutzberg C, Amant F, Bosse T, González-Martín A, Ledermann J, et al; ESMO-ESGOESTRO Endometrial Consensus Conference Working Group. ESMO-ESGO-ESTRO Consensus Conference on Endometrial Cancer: Diagnosis, Treatment and Follow-up. Int J Gynecol Cancer 2016;26(1):2-30.

5. Reid-Nicholson M, Iyengar P, Hummer AJ, Linkov I, Asher M, Soslow RA. Immunophenotypic diversity of endometrial adenocarcinomas: implications for differential diagnosis. Mod Pathol 2006;19(8):1091-100.

6. Bokhman JV. Two pathogenetic types of endometrial carcinoma. Gynecol Oncol 1983;15(1):10-7.

7. Gottwald L, Pluta P, Piekarski J, Spych M, Hendzel K, Topczewska-Tylinska $\mathrm{K}$, et al. Long-term survival of endometrioid endometrial cancer patients. Arch Med Sci 2010;6(6):937-44.

8. Morice P, Leary A, Creutzberg C, Abu-Rustum N, Darai E. Endometrial cancer. Lancet 2016;387(10023):1094108.
9. Zeimet AG, Reimer D, Huszar M, Winterhoff B, Puistola U, Azim SA, et al. L1CAM in early-stage type I endometrial cancer: results of a large multicenter evaluation. J Natl Cancer Inst 2013;105(15):1142-50. 10. Cancer Genome Atlas Research Network, Kandoth C, Schultz N, Cherniack AD, Akbani R, Liu Y, Shen H, et al. Integrated genomic characterization of endometrial carcinoma. Nature 2013;497(7447):67-73.

11. Mariani A, Dowdy SC, Cliby WA, Gostout BS, Jones $\mathrm{MB}$, Wilson TO, et al. Prospective assessment of lymphatic dissemination in endometrial cancer: a paradigm shift in surgical staging. Gynecol Oncol 2008;109(1):11-8.

12. ASTEC study group, Kitchener $H$, Swart AM, Qian Q, Amos C, Parmar MK. Efficacy of systematic pelvic lymphadenectomy in endometrial cancer (MRC ASTEC trial): a randomised study. Lancet 2009;373(9658):125-36.

13. Benedetti Panici P, Basile S, Maneschi F, Alberto Lissoni A, Signorelli M, Scambia G, et al. Systematic pelvic lymphadenectomy vs. no lymphadenectomy in early-stage endometrial carcinoma: randomized clinical trial. J Natl Cancer Inst 2008;100(23):1707-16.

14. Todo Y, Kato H, Kaneuchi M, Watari H, Takeda M, Sakuragi N. Survival effect of para-aortic lymphadenectomy in endometrial cancer (SEPAL study): a retrospective cohort analysis. Lancet 2010;375(9721):1165-72.

15. Kilgore LC, Partridge EE, Alvarez RD, Austin JM, Shingleton HM, Noojin F 3rd, et al. Adenocarcinoma of the endometrium: survival comparisons of patients with and without pelvic node sampling. Gynecol Oncol 1995;56(1):29-33.

16. Lutman CV, Havrilesky LJ, Cragun JM, Secord AA, Calingaert B, Berchuck A, et al. Pelvic lymph node count is an important prognostic variable for FIGO stage I and II endometrial carcinoma with high-risk histology. Gynecol Oncol 2006;102(1):92-7.

17. Abu-Rustum NR, Iasonos A, Zhou Q, Oke E, Soslow $\mathrm{RA}$, Alektiar KM, et al. Is there a therapeutic impact to regional lymphadenectomy in the surgical treatment of endometrial carcinoma? Am J Obstet Gynecol 2008;198(4):457.e1-5.

18. Cragun JM, Havrilesky LJ, Calingaert B, Synan I, Secord AA, Soper JT, et al. Retrospective analysis of selective lymphadenectomy in apparent early-stage endometrial cancer. J Clin Oncol 2005;23(16):3668-75.

19. Creasman WT, Morrow CP, Bundy BN, Homesley HD, Graham JE, Heller PB. Surgical pathologic spread patterns of endometrial cancer. A Gynecologic Oncology Group Study. Cancer 1987;60(8 Suppl):2035-41.

20. Vargas R, Rauh-Hain JA, Clemmer J, Clark RM, Goodman A, Growdon WB, et al. Tumor size, depth 
of invasion, and histologic grade as prognostic factors of lymph node involvement in endometrial cancer: a SEER analysis. Gynecol Oncol 2014;133(2):216-20.

21. Beesley VL, Rowlands IJ, Hayes SC, Janda M, O'Rourke $\mathrm{P}$, Marquart L, et al. Incidence, risk factors and estimates of a woman's risk of developing secondary lower limb lymphedema and lymphedema-specific supportive care needs in women treated for endometrial cancer. Gynecol Oncol 2015;136(1):87-93.

22. Aalders J, Abeler V, Kolstad P, Onsrud M. Postoperative external irradiation and prognostic parameters in stage I endometrial carcinoma: clinical and histopathologic study of 540 patients. Obstet Gynecol 1980;56(4):419-27.

23. Onsrud M, Cvancarova M, Hellebust TP, Tropé CG, Kristensen GB, Lindemann K. Long-term outcomes after pelvic radiation for early-stage endometrial cancer. J Clin Oncol 2013;31(31):3951-6.

24. Nout RA, van de Poll-Franse LV, Lybeert ML, Wárlám-Rodenhuis CC, Jobsen JJ, Mens JW, et al. Longterm outcome and quality of life of patients with endometrial carcinoma treated with or without pelvic radiotherapy in the post operative radiation therapy in endometrial carcinoma 1 (PORTEC-1) trial. J Clin Oncol 2011;29(13):1692-700.

25. Creutzberg CL, van Putten WL, Koper PC, Lybeert ML, Jobsen JJ, Wárlám-Rodenhuis CC, et al. Surgery and postoperative radiotherapy versus surgery alone for patients with stage-1 endometrial carcinoma: multicentre randomised trial. PORTEC Study Group. Post Operative Radiation Therapy in Endometrial Carcinoma. Lancet 2000;355(9213):1404-11.

26. Creutzberg CL, van Putten WL, Koper PC, Lybeert ML, Jobsen JJ, Wárlám-Rodenhuis CC, et al. The morbidity of treatment for patients with Stage I endometrial cancer: results from a randomized trial. Int J Radiat Oncol Biol Phys 2001;51(5):1246-55.

27. ASTEC/EN.5 Study Group, Blake P, Swart AM, Orton J, Kitchener H, Whelan T, Lukka H, et al. Adjuvant external beam radiotherapy in the treatment of endometrial cancer (MRCASTEC and NCIC CTG EN.5 randomised trials): pooled trial results, systematic review, and meta-analysis. Lancet 2009;373(9658):13746.

28. Keys HM, Roberts JA, Brunetto VL, Zaino RJ, Spirtos NM, Bloss JD, et al. A phase III trial of surgery with or without adjunctive external pelvic radiation therapy in intermediate risk endometrial adenocarcinoma: a Gynecologic Oncology Group study. Gynecol Oncol 2004;92(3):744-51.

29. Kong A, Johnson N, Kitchener HC, Lawrie TA. Adjuvant radiotherapy for stage I endometrial cancer: an updated Cochrane systematic review and meta-analysis. J Natl Cancer Inst 2012;104(21):1625-34.

30. Sorbe B, Nordström B, Mäenpää J, Kuhelj J, Kuhelj D, Okkan S, et al. Intravaginal brachytherapy in FIGO stage I low-risk endometrial cancer: a controlledrandomized study. Int J Gynecol Cancer 2009;19(5):873-8.

31. Nout RA, Smit VT, Putter H, Jürgenliemk-Schulz IM, Jobsen JJ, Lutgens LC, et al; PORTEC Study Group. Vaginal brachytherapy versus pelvic external beam radiotherapy for patients with endometrial cancer of high-intermediate risk (PORTEC-2): an open-label, non-inferiority, randomised trial. Lancet 2010;375(9717):816-23.

32. Sorbe B, Horvath G, Andersson H, Boman K, Lundgren $\mathrm{C}$, Pettersson B. External pelvic and vaginal irradiation versus vaginal irradiation alone as postoperative therapy in medium-risk endometrial carcinoma-a prospective randomized study. Int J Radiat Oncol Biol Phys 2012;82(3):1249-55.

33. Wortman BG, Creutzberg CL, Putter H, JürgenliemkSchulz IM, Jobsen JJ, Lutgens LCHW, et al. Ten-year results of the PORTEC-2 trial for high-intermediate risk endometrial carcinoma: improving patient selection for adjuvant therapy. Br J Cancer 2018;119(9):106774.

34. Gadducci A, Cavazzana A, Cosio S, DI Cristofano C, Tana R, Fanucchi A, et al. Lymph-vascular space involvement and outer one-third myometrial invasion are strong predictors of distant haematogeneous failures in patients with stage I-II endometrioid-type endometrial cancer. Anticancer Res 2009;29(5):1715-20.

35. Gemer O, Arie AB, Levy T, Gdalevich M, Lorian M, Barak F, et al. Lymphvascular space involvement compromises the survival of patients with stage I endometrial cancer: results of a multicenter study. Eur J Surg Oncol 2007;33(5):644-7.

36. Guntupalli SR, Zighelboim I, Kizer NT, Zhang Q, Powell MA, Thaker PH, et al. Lymphovascular space invasion is an independent risk factor for nodal disease and poor outcomes in endometrioid endometrial cancer. Gynecol Oncol 2012;124(1):31-5.

37. Bosse T, Peters EE, Creutzberg CL, JürgenliemkSchulz IM, Jobsen JJ, Mens JW, et al. Substantial lymph-vascular space invasion (LVSI) is a significant risk factor for recurrence in endometrial cancer--A pooled analysis of PORTEC 1 and 2 trials. Eur J Cancer 2015;51(13):1742-50.

38. Kunneman M, Pieterse AH, Stiggelbout AM, Nout RA, Kamps M, Lutgens LC, et al. Treatment preferences and involvement in treatment decision making of patients with endometrial cancer and clinicians. $\mathrm{Br}$ J Cancer 2014;111(4):674-9. 
39. Rydzewski NR1, Strohl AE2, Donnelly ED3, Kanis MJ, Lurain JR, Nieves-Neira W, et al. Receipt of vaginal brachytherapy is associated with improved survival in women with stage I endometrioid adenocarcinoma of the uterus: A National Cancer Data Base study. Cancer 2016;122(23):3724-31.

40. Chino JP, Jones E, Berchuck A, Secord AA, Havrilesky LJ. The influence of radiation modality and lymph node dissection on survival in early-stage endometrial cancer. Int J Radiat Oncol Biol Phys 2012;82(5):1872-9.

41. Harkenrider MM, Adams W, Block AM, Kliethermes S, Small W Jr, Grover S. Improved overall survival with adjuvant radiotherapy for high-intermediate and high risk Stage I endometrial cancer. Radiother Oncol 2017;122(3):452-7.

42. McMeekin DS, Filiaci VL, Aghajanian C, Cho J, Kim JW, DiSilvestro P, et al. A randomized phase III trial of pelvic radiation therapy (PXRT) versus vaginal cuff brachytherapy followed by paclitaxel/carboplatin chemotherapy $(\mathrm{VCB} / \mathrm{C})$ in patients with high risk (HR), early stage endometrial cancer (EC): A Gynecologic Oncology Group trial. Gynecol Oncol. 2014; $134: 438$.

43. Hogberg T, Signorelli M, de Oliveira CF, Fossati R, Lissoni AA, Sorbe B, et al. Sequential adjuvant chemotherapy and radiotherapy in endometrial cancer-results from two randomised studies. Eur J Cancer 2010;46(13):2422-31.

44. de Boer SM, Powell ME, Mileshkin L, Katsaros D, Bessette $\mathrm{P}$, Haie-Meder C, et al. Adjuvant chemoradiotherapy versus radiotherapy alone for women with highrisk endometrial cancer (PORTEC-3): final results of an international, open-label, multicentre, randomised, phase 3 trial. Lancet Oncol 2018;19(3):295-309.

45. Wright JD, Fiorelli J, Kansler AL, Burke WM, Schiff PB, Cohen CJ, et al. Optimizing the management of stage II endometrial cancer: the role of radicalhysterectomy and radiation. Am J Obstet Gynecol 2009;200(4):419. e1-7.

46. Bingham B, Orton A, Boothe D, Stoddard G, Huang YJ, Gaffney DK, et al. Brachytherapy Improves Survival in Stage III Endometrial Cancer With Cervical Involvement. Int J Radiat Oncol Biol Phys 2017;97(5):1040-50.

47.PORTEC 4. Available at: https://www.maastro.nl/ en/5/428/portec-4.aspx. Accessed Mar 18, 2015.

48. Nag S, Erickson B, Parikh S, Gupta N, Varia M, Glasgow G. The American Brachytherapy Society recommendations for high-dose-rate brachytherapy for carcinoma of the endometrium. Int J Radiat Oncol Biol Phys 2000;48(3):779-90.

49. Small W Jr, Beriwal S, Demanes DJ, Dusenbery KE, Eifel P, Erickson B, et al. American Brachytherapy
Society consensus guidelines for adjuvant vaginal cuffbrachytherapy after hysterectomy. Brachytherapy 2012;11(1):58-67.

50. Klopp A, Smith BD, Alektiar K, Cabrera A, Damato $\mathrm{AL}$, Erickson B, et al. The role of postoperative radiation therapy for endometrial cancer: Executive summary of an American Society for Radiation Oncology evidence-based guideline. Pract Radiat Oncol 2014;4(3):137-44.

51. Humphrey P, Cornes P, Al-Booz H. Vaginal vault brachytherapy in endometrial cancer: verifying target coverage with image-guided applicator placement. $\mathrm{Br}$ J Radiol 2013;86(1023):20120428.

52. Cameron AL, Cornes $\mathrm{P}, \mathrm{Al}-\mathrm{Booz} \mathrm{H}$. Brachytherapy in endometrial cancer: quantification of air gaps around a vaginal cylinder. Brachytherapy 2008;7(4):355-8.

53. Richardson S, Palaniswaamy G, Grigsby PW. Dosimetric effects of air pockets around high-dose rate brachytherapy vaginal cylinders. Int J Radiat Oncol Biol Phys 2010;78(1):276-9.

54. Harkenrider MM, Grover S, Erickson BA, Viswanathan AN, Small C, Kliethermes S, et al. Vaginal brachytherapy for postoperative endometrial cancer: 2014 Survey of the American Brachytherapy Society. Brachytherapy 2016;15(1):23-9.

55. Bahadur YA, Constantinescu C, Hassouna AH, Eltaher MM, Ghassal NM, Awad NA. Single versus multichannel applicator in high-dose-rate vaginal brachytherapy optimized by inverse treatment planning. J Contemp Brachytherapy 2015;6(4):362-70.

56. El Khoury C, Dumas I, Tailleur A, Morice P, HaieMeder C. Adjuvant brachytherapy for endometrial cancer: advantages of the vaginal mold technique. Brachytherapy 2015;14(1):51-5.

57. Tuncel N, Garipagaoglu M, Kizildag AU, Andic F, Toy A. Optimisation techniques in vaginal cuff brachytherapy. Br J Radiol 2009;82(983):936-40.

58. Fayed A, Mutch DG, Rader JS, Gibb RK, Powell MA, Wright JD, et al. Comparison of high-dose-rate and low-dose-rate brachytherapy in the treatment of endometrial carcinoma. Int J Radiat Oncol Biol Phys 2007;67(2):480-4.

59. MacLeod C, Fowler A, Duval P, D’Costa I, Dalrymple C, Firth I, et al. High-dose-rate brachytherapy alone post-hysterectomy for endometrial cancer. Int J Radiat Oncol Biol Phys 1998;42(5):1033-9.

60. Owens K, Patel H, Yashar C, Spanos WJ. Vaginal cuff brachytherapy for endometrial carcinoma: Results of limiting vaginal coverage to one centimeter length. Brachytherapy 2007;6(2):98-9.

61. Kloetzer KH, Günther R, Wendt T. The vaginal stump recurrence rate in endometrial carcinoma in relation 
to the target volume of postoperative HDR-afterloading brachytherapy. [Article in German]. Strahlenther Onkol 1997;173(1):13-7.

62. Choo JJ, Scudiere J, Bitterman P, Dickler A, Gown AM, Zusag TW. Vaginal lymphatic channel location and its implication for intracavitary brachytherapy radiation treatment. Brachytherapy 2005;4(3):236-40.

63. Li S, Aref I, Walker E, Movsas B. Effects of prescription depth, cylinder size, treatment length, tip space, and curved end on doses in high-dose-rate vaginal brachytherapy. Int J Radiat Oncol Biol Phys 2007;67(4):1268-77.

64. Sabater S, Andres I, Lopez-Honrubia V, Berenguer R, Sevillano M, Jimenez-Jimenez E, et al. Vaginal cuff brachytherapy in endometrial cancer - a technically easy treatment? Cancer Manag Res 2017;9:351-62.

65. Iatì G, Pontoriero A, Mondello S, Brogna A, Di Pasquale A, Ielo I, et al. Three-dimensional treatment planning for vaginal cuff brachytherapy: dosimetric effectson organs at risk according to patients position. Brachytherapy 2014;13(6):568-71.

66. Hoskin PJ, Bownes P, Summers A. The influence of applicator angle on dosimetry in vaginal vault brachytherapy. Br J Radiol 2002;75(891):234-7.

67. Sabater S, Arenas M, Berenguer R, Machin-Hamalainen S, Andres I, Sevillano MM, et al. Dosimetric analysis of rectal filling on rectal doses during vaginal cuff brachytherapy. Brachytherapy 2015;14(4):458-63.

68. Sabater S, Andrés I, Gascon M, Rovirosa A, Sevillano $M$, Berenguer R, et al. Effect of rectal enemas on rectal dosimetric parameters during high-dose-rate vaginal cuff brachytherapy: A prospective trial. Strahlenther Onkol 2016;192(4):248-53.

69. Andres I, Gutierrez-Perez M, Rodriguez-Vela MP,
Berenguer R, Sevillano M, Aguayo M, et al. The usefulness of fleet rectal enemas on high-dose-rate intracavitary cervical cancerbrachytherapy. A prospective trial. J Contemp Brachytherapy 2017;9(3):224-9.

70. Hung J, Shen S, De Los Santos JF, Kim RY. Imagebased 3D treatment planning for vaginal cylinder brachytherapy: dosimetriceffects of bladder filling on organs at risk. Int J Radiat Oncol Biol Phys 2012;83(3):980-5.

71. Guler OC, Onal C, Acibuci I. Effects of bladder distension on dose distribution of vaginal vault brachytherapy in patients with endometrial cancer. J Contemp Brachytherapy 2015;6(4):371-6.

72. Stewart AJ, Cormack RA, Lee H, Xiong L, Hansen JL, O'Farrell DA, et al. Prospective clinical trial of bladder filling and three-dimensional dosimetry in high-doserate vaginal cuff brachytherapy. Int J Radiat Oncol Biol Phys 2008;72(3):843-8.

73. Corso CD, Jarrio C, Nunnery EW, Ali AN, Ghavidel $\mathrm{S}$, Rossi PJ, et al. Dosimetric and cost comparison of first fraction imaging versus fractional re-imaging on critical organ dose in vaginal cuff brachytherapy. Pract Radiat Oncol 2013;3(4):256-62.

74. Holloway CL, Macklin EA, Cormack RA, Viswanathan AN. Should the organs at risk be contoured in vaginal cuff brachytherapy? Brachytherapy 2011;10(4):313-7.

75. Chapman CH, Prisciandaro JI, Maturen KE, Cao Y, Balter JM, McLean K, et al. MRI-Based Evaluation of the Vaginal Cuff in Brachytherapy Planning: Are We Missing the Target? Int J Radiat Oncol Biol Phys 2016;95(2):743-50.

76. Kim H, Kim H, Houser C, Beriwal S. Is there any advantage to three-dimensional planning for vaginal cuff brachytherapy? Brachytherapy 2012;11(5):398-401. 